\title{
Creation of an Observational Instrument to Operationalize the Transmission of Contents by University Teachers
}

\author{
Africa Borges ${ }^{1}$, Cristina Falcón ${ }^{1}$ \& Matilde Díaz ${ }^{2}$ \\ ${ }^{1}$ Department of Psicología Clínica, Psicobiología y Metodología, Sección de Psicología, University of La Laguna. \\ ${ }^{2}$ Department of Psicología Cognitiva, Social y Organizacional, Sección de Psicología, University of La Laguna. \\ Correspondence: Africa Borges, Sección de Psicología, Campus de Guajara, 38205 La Laguna, Santa Cruz de Tenerife, \\ Spain.
}

Received: May 9, 2016

doi:10.11114/ijsss.v4i7.1596
Accepted: May 26, $2016 \quad$ Available online: June 7, 2016

URL: http://dx.doi.org/10.11114/ijsss.v4i7.1596

\begin{abstract}
The quality of university teaching is a very important aspect for the educational process. This aspect makes necessary the evaluation of teaching professionals, being of special relevance the teaching behavior in the classroom. Observational methodology is the one used for evaluation, because it allows the study of usual behavior patterns and teaching strategies. We have used the instrument PROFUNDO-UNI, which is based on the "Teaching Functions Model", to analyze the behaviors of the university teachers and professors in the class. The objective of this study is the detailed analysis of one of the teaching functions described in this instrument. This function is the professor's explanation. It is a function of particular relevance in the educational setting, so it is very important to analyze it. For that, an instrument named Observational Protocol of the Explanation Function (OBEF) was created based on contributions of Educational Psychology. It allows the measurement of the resources and strategies used during the explanation. In this investigation, the psychometric goodness of fit has been tested through the analysis of reliability and homogeneity. Later, the behavior of a teacher from the University of La Laguna has been analyzed by using the instrument that was created.
\end{abstract}

Keywords: observational methodology, teacher explanation, teaching function model, Educational Psychology, psychometric goodness of fit.

\section{Introduction}

Nowadays, the main challenge in Education is quality, which can be proved by the efforts made in many countries by developing quality policies. For this reason, evaluation is one of the most relevant topics in education (Roman \& Murillo, 2013).

Educational process is multimodal, being necessary to evaluate several factors included in the teaching - learning approach: institutions, educational systems, educational programs, students' learning process and the teacher (Mateo \& Martínez, 2008).

The evaluation of teachers is one of the most important factors since it is a key figure in the educational setting. Their behaviors are the goal of study and research, given the importance they have on the delivery of content and, ultimately, the development of effective teaching. Undoubtedly, quality education implies quality teachers (Galán, González-Galán \& Rodríguez-Patrón, 2014; Martínez, 2013).

The relevant role of the teacher in the teaching-learning process is revealed by institutional politics designed to evaluate them. In Spain, there is a program named Docentia, created to evaluate the quality of university teachers. It provides support to Universities when designing different systems of quality assessment of teaching activity. This is done from a formative perspective, where the information provided is intended to guide the future professional; and summative, helping to make decisions about incentives, continuity and professional development (Martínez, 2013). It includes topics like formative courses received by lecturers, characteristics of their classes (number of students in the classroom, types of topics, etc.) and research, among others.

Given the importance of teachers in the instructional setting, Hernandez (2005) uses six actions to identify educational effectiveness: believe, know, can, want, be and do. Danielson's (2007) model of assessment identifies four dimensions to define quality teaching practices: planning and preparation, classroom environment, teaching and professional 
responsibilities. The Teaching Functions model (Hernandez, 1991; Hernandez-Jorge, 2005) systematizes and equates teaching functions with behaviors, giving the teacher's behaviors an educational sense. This conducts are grouped into eight functions: organization, communicability, motivation, behavioral control, interaction, assessment, self-report or continuing training, guidance and customization.

The importance of educational functions has been proved in several researches. The planning function contributes to greater validity in the teaching-learning process (Boekaerts, 2002; Hernández, 2006). Teacher's feedback and student's participation in the classroom are related to higher academic achievement (Lane, Wehby \& Menzies, 2003). The behavioral control has great educational value as a social function, because it teaches how to put yourself in another person's place, and it plays an important role in the acquisition of self-control (Muñoz de Bustillo and Rodriguez, 2001). There is also evidence supporting the importance of guidance and counselling, active monitoring as a positive influence on student's behavior, reducing incidents in the classroom and encouraging greater student participation (De Pry \& Sugai, 2002; Schuldheisz \& van der Mars, 2001).

One of the most important conduct is the explanation of content by teachers, part of the function of teaching communicability. This is a fundamental conduct for teachers, which clearly conveys information, structure and makes education understandable (Hernandez-Jorge, 2005).

Some strategies that help students to access information have been identified, such as previous schemes given to students, structure and organization, and how to apply information (Hernández, 1991; Hernández \& García, 1995). Other way to classify these strategies depends on the type of information: the information derives from teacher's explanation or other external information. (Jiménez \& Hernández-Jorge, 2001). Hernández-Jorge (2005) classified the strategies used to transmit information:

- Rising the students' attention: changes made to capture their attention and also increase their motivation.

- Giving meaning to information and making it understandable: at the beginning of the class, on a general level, through the use of advanced organizers; during the development of the class, on a specific level, familiar language and redundancies or synonyms, explanation, exemplification, analogies or metaphors are used.

- Structuring and integrating information: indexes or scripts, graphics to organize information, conceptual models or conceptual maps.

- Developing and producing information. The following strategies are used so the students are able to generate new knowledge: connect the information to what the already know, apply the information, transfer and use logical wheels and study strategies.

In order to determine the quality of teachers, it is essential to assess their professional development through various measuring instruments, such as standardized tests, surveys and interviews with teachers and students, portfolio, value-added models and observations in class (Martínez, 2013).

Observational methodology constitutes one of the best procedures to study human behavior in natural settings (Blanco, Sastre \& Escolano, 2010). It is a rigorous and complex methodology with several advantages, such as obtaining large amount of information, analyzing behavior in natural situations, which is why it is very useful in the evaluation of teaching performance. However, there is a need to develop observational instruments with psychometric goodness applied by carefully trained observers (Díaz, 2014; Rodriguez-Naveiras, Borges \& Cadenas, 2014).

Several observational instruments have been used in the classroom, as The Classroom Assessment Scoring System Class, which evaluates key dimensions in the classroom from kindergarten to third grade (La Paro, Stuhlman \& Pianta, 2004), or the Framework for Teaching, where different domains, such as planning and preparation of the class, classroom environment, instruction and professional responsibilities are evaluated (Martínez-Rizo, 2012).

In the university level, and based on the Teaching Functions model (Hernandez-Jorge, 2005) the Observation Protocol of Teaching Functions in University teachers (OPTFU, Protocolo de Observación de Funciones docentes en Universidad, PROFUNDO-UNI, in its Spanish version, Díaz, 2014) has been developed to measure behaviors and behavioral patterns of university teachers and students within the classroom. Teaching functions are operationalized, but without detailing the specific strategies used in each function.

The objective of this research is to create an observational instrument that is linked with the PROFUNDO-UNI (Diaz, 2014), designed to analyze in detail the behavior Explanation, given the great importance for the transmission of knowledge in the teaching-learning process. Secondly, we test the created instrument by analyzing a university teacher's behavior in the classroom. 


\section{Method}

\subsection{Methodology and Design}

Observational methodology has been used in this research. A nomothetic, follow-up observation and multidimensional design was used (Anguera, Blanco \& Losada, 2001).

\subsection{Participants}

In order to create the instrument, we contacted five university teachers of the University of La Laguna and we asked authorization to record their classes and their students while they were teaching. They belonged to different knowledge areas: three of Health Sciences, one of Engineering and one of Chemistry. They were between 40 and 60 years old.

Later, to test the created instrument, the explanation behavior of a female university teacher belonging to Health Sciences was used to test the applicability of the instrument to real data.

The observation of the behaviors is made by two expert female observers, one with a $\mathrm{PhD}$. in Psychology and an undergraduate student.

\subsection{Instrument}

The observational instrument used in this research was created ad hoc to operationalize the way university teachers transmit information and knowledge to their students, named Observation Protocol of the Explanation Function (OBEF, Protocolo de Observación de la Función de Explicación, PROFE in it Spanish version). Their structure is shown in table 1.

To create the instrument, the educational theories about how the information is transmitted to their students were followed. All the strategies, resources or observable styles that university teachers used during the theoretical exposition of the contents were collected. Thus, the first version of the instrument was completed. The instrument combines category systems and field formats. Each category is exhaustive and mutually exclusive and, different codes are grouped together based on the criteria established in the empirical study (Anguera \& Hernández-Mendo, 2013).

The instrument is formed by three criteria: Content Organization, Relation to the Contents, and Contrast Stimuli. It also includes an instrumental criteria designed to maintain the flow of behaviors, when the conduct emitted by the university teacher cannot be registered.

The criterion Content Organization includes the strategies directed to structure, classification, and integrate information. This is how these strategies allow establishing a relationship between the parts and the whole, in addition to distinguishing between which information is fundamental and which one is only complementary (García, 1998).

The criterion Relation to the Contents is related with the theory content that the university teacher wants to transmit to their student and three types of strategies compose it. The first one is related with the strategies directed to transmit information (Lineal Explanation, Explanation with resources, Repetition, Definition and Dictation). The second one is based on advanced organizers (Ausubel, 1978), directed to establish a connection between what students know and what they need to know: Use of synonyms and Analogies. Finally, Generalizations are used in order to the student can generate new knowledge.

The strategies which include changes directed to capture the attention of the students belong to the criterion Contrast Stimuli. It is based in the Gestalt principle "figure-background" (Hernández-Jorge, 2005).

Lastly, the Instrumental criterion is used to maintain a continuous flow of conduct in the codification process.

\subsection{Procedure}

For each university teacher eight hours were recorded. Two of them were selected for the creation of the instrument, making sure they had the clearest image and sound.

When the instrument construction process finished, ten sessions of the total were codified to test its psychometric adequacy in reliability (both with Kappa coefficient and Generalizability Theory, TG) and homogeneity (with TG). Then, the obtained coefficients were compared with the following criteria: at least 0.75 in the case of Kappa coefficient (Fleiss, 1981), 0.80 for reliability calculated by TG (Volpe, Briesch \& Gadow, 2011) and 0 for the homogeneity (Castellano, Hernández-Mendo, Gómez de Segura, Fontetxa, \& Bueno, 2000). When the criteria were not reached, several changes were made to the instrument, creating a new version of it. This process continued until the criteria values were reached.

Finally, to test the applicability of the instrument to real data, two class sessions of one of the university teachers were chosen. Afterwards, her behaviors were codified by the Generalizability Theory (TG; Cronbach, Gleser, Nanda \& Rajaratnam, 1972) to determine the time optimization (Borges \& Rodríguez-Dorta, in press, a; Rodríguez-Dorta \& Borges, 2015). 
Table 1. Observation Protocol of the Explanation Function

\begin{tabular}{|c|c|c|}
\hline STANDART & CODES & \\
\hline \multirow{7}{*}{ Content Organization } & Synthesise & SN \\
\hline & Scheme & $\mathrm{SC}$ \\
\hline & Connecting with previous contents & $\mathrm{CP}$ \\
\hline & Connecting with following contents & $\mathrm{CF}$ \\
\hline & Presentation of Objective & $\mathrm{PO}$ \\
\hline & Lineal explanation & EX \\
\hline & Explanation with resources & ER \\
\hline \multirow{7}{*}{ Relation to the Contents } & Repetition & $\mathrm{RP}$ \\
\hline & Definition & $\mathrm{DF}$ \\
\hline & Lecture & LC \\
\hline & Dictation & DC \\
\hline & Use of synonyms & US \\
\hline & Analogies & AN \\
\hline & Generalization & GE \\
\hline \multirow{5}{*}{ Contrast Stimuli } & Anecdotes & $\mathrm{AD}$ \\
\hline & Sound change & $\mathrm{SC}$ \\
\hline & Use of humour & $\mathrm{UH}$ \\
\hline & General interactions & GI \\
\hline & Unobservable & $\mathrm{Y}$ \\
\hline Instrumentals & Interruption & IN \\
\hline
\end{tabular}

\subsection{Data Analysis}

To analyze reliability, two coefficients were calculated: Kappa Coefficient (Cohen, 1960) and Generalizability Theory (TG, (Cronbach, Gleser, Nanda \& Rajaratnam, 1972), because they offer complementary information: While Kappa coefficient (calculated by the SPSS v15 program) establishes a relationship higher than chance between the observers agreement and the potential one, the TG objective is to measure and to identify the variability components which introduce error to the actual context, developing strategies to reduce its influence in the measurement (Blanco-Villaseñor, 1991). TG was calculated by the SGAT v. 1.0. Program (Ramos, Hernández, Pastrana \& Blanco, 2012).

The university teacher's behavior is analyzed at a macro-analysis level (Sarria, 2010) calculating the relative frequency as a parameter, and using micro-analysis from the perspective of sequential analysis (Bakeman \& Quera, 1996) to determine behavior patterns, through the SDIS-GSEQ v5.1 program (Bakeman \& Quera, 1996). This programs calculates which behavior follows another with a probability higher than chance, taking as a reference an antecedent behavior (behavior given) that follows it directly in the first lag. The dependence is positive when $\mathrm{Z}$ is higher than 1.96. To study the association value, the Yule's Q coefficient (Yule \& Kendal, 1957) was calculated, also using the SDIS-GSEQ, v. 5.1 programs (Bakeman \& Quera, 1996).

\section{Results}

\subsection{Purifying the instrument}

To purify the instrument, the agreement between observers was calculated by Kappa Coefficient (0.622) and TG (0.904). A cross facet design is used $\mathrm{OxC}$, following a random effects Estimation plan. In the measurement plan, the observers are considered as facet of differentiation and the Codes as facet of generalization or instrumentation $(\mathrm{O} / \mathrm{C})$.

To assess the homogeneity of the instrument, a cross facet design is used, $\mathrm{OxC}$, following a random effects Estimation plan, where the Observers are considered as facet of differentiation and the Codes as facet of generalization or 
instrumentation (Measurement plan O/C). The coefficient obtained was 0.522.

Results showed that only reliability calculated by TG reach criteria, whereas the other coefficient are below it.

For this reason, we purify the instrument, introducing the following changes: the code Objectives presentation was removed, because it is difficult to differentiate to the Scheme code, which was redefined to expose with clarity when it is codified. The same procedure was followed by the code Repetition. These changes are reflected on the second version of the instrument, and with them reliability and homogeneity were calculated again. Whereas the criteria were reached (Kappa $=0.886$; reliability by $\mathrm{TG}=0.963$, and homogeneity $=0$ ), several problems were found in the codes Lecture and Sound Change. In this case, no new codes were included, but the explanations about the mentioned codes were redefined. Therefore, the third version of the instrument was established. Again, reliability and homogeneity were calculated, reaching criteria: Kappa $=1$; reliability by $\mathrm{TG}=0.912$; homogeneity $=0$. With these results, we concluded that the instrument has psychometric adjustment.

\subsection{The Measure of the Explanation Behavior in A University Teacher}

To see how the instrument works, we analyzed the explanation behavior of a university teacher.

The first step is to determine the number of sessions that had to be codified. For this, the optimization of the Generalizability Theory was used (Ramos, Hernández, Pastrana \& Blanco, 2012), with a cross facet design, CxS, following a random effects Estimation plan, where the Codes are considered as facet of differentiation and the sessions as facet of generalization or instrumentation (Measurement plan C/S). The coefficient obtained with two sessions was 0.99. For this reason, no more sessions were coded.

Taking into account that university teacher's behavior is not the same in the beginning of the class session, in the middle and the end, codification follows these three moments. The beginning and the end of the class has been fixed observing how much time the university teacher dedicated to them, selecting the maximum time (exactly five minutes for each). To calculate the minimum time during the development of the class, the optimization analysis of the GT was calculated again (Rodríguez Dorta \& Borges, 2015; Rodríguez-Dorta, Cadenas \& Díaz-Hernández, 2011), with a cross facet design, CxT, following a random effects Estimation plan, where the Codes are considered as facet of differentiation and the Time as facet of generalization or instrumentation (Measurement plan C/T), using five minutes stretches of time as unit. The coefficient obtained with two five minutes stretches of time was 0.93 . For this reason, ten minutes of two sessions were coded.

Secondly, the relative frequency of each behavior has been calculated (see table 2). Unsurprisingly, lineal explanation has the largest frequency, even in the end of the class. But she used other resources to transmit contents to her pupils, relating to the three categories that the instrument collects.

Table 2. Codes relative frequency

\begin{tabular}{ccccc}
\hline & Beginning & End & Middle \\
\hline $\begin{array}{c}\text { Connecting with previous } \\
\text { contents }\end{array}$ & 0 & 0.02 & Connecting with previous & 0.02 \\
$\begin{array}{c}\text { contents } \\
\text { Connecting with following } \\
\text { contents }\end{array}$ & 0 & 0 & Connecting with following & 0.02 \\
Lineal explanation & 0.09 & 0.17 & Lineal explanation & 0.22 \\
Explanation with resources & 0 & 0.06 & Explanation with resources & 0.06 \\
Examples & 0.04 & 0 & Examples & 0.06 \\
Generalizations & 0 & 0.02 & Generalizations & 0 \\
Definition & 0.02 & 0 & Definition & 0.01 \\
Anecdotes & 0.02 & 0.06 & Anecdotes & 0.05 \\
Humour use & 0 & 0.02 & Humour use & 0.01 \\
General interactions & 0.02 & 0 & General interactions & 0.01 \\
\hline
\end{tabular}

Sequential analysis is most important in observational data, because it not only allows discovering the type and frequency with which behavior appears, but the patterns of behaviors. For this reason, a sequential lag analysis was performed (Bakerman and Quera, 1996). All the behaviors occurring at least with a relative frequency higher than 0.03 are included as given behavior. It was found that neither beginning nor end pattern behavior was significant. The significant patterns in the developing phase of the class are showed in table 3 , with the relationship between behaviors, 
calculated by the Yule's Q, presented in the right column.

There are two behaviors which produce significant patterns: Example and Lineal Explanation. Explanation can be followed by Lineal explanation or Humor use. The other behavior is more relevant, Lineal explanation. Results show that the university teacher had several strategies to communicate information to her student, because her explanation was followed by strategies that establish relations with contents (definition, examples, explanation with resources), which serve as organizing the content (Connecting with following contents) or implies a contrast stimuli (anecdotes).

Table 3. Sequential Analysis.

\begin{tabular}{ccc}
\hline Antecedent behavior & Consequent Behavior & \multirow{2}{*}{ Q de Yule } \\
\hline Codes & Lag I. Excitatory & 0,61 \\
& Lineal explanation (2.04) & In \\
& Humor use (5.70) & \\
& Anecdotes (3.23) & 0.82 \\
& Connecting with following contents (3.29) & In \\
& Definition (2.68) & In \\
Lineal Explanation & Example (2.84) & 0.75 \\
& Resources explanation (2.84) & 0.75 \\
\hline
\end{tabular}

Note. In=Indefinite

The Yule's Q showed that the relationship between the behavior that compose the pattern was moderate or high, because in all cases they are higher than 0.50 . However, when any of the cells of the contingency table is zero, it is not possible to calculate the Yule's Q, which is indefinite (In).

\section{Discussion}

The assessment of university teachers' behavior while they are teaching their class is a very important way to evaluate the quality of university education. But evaluation means using accurate measurement instruments, as we present here.

The aim of this research was to create an observational instrument, the Observational Protocol of Explanation Function (OPEF), which completes the previous Observational Protocol of Teaching Functions in University (OPTFU, Diaz, 2014). It allows to study how the behaviors that university teachers do in the classroom have one specific teaching function, and also the behavior patterns they generate. The mentioned instrument has showed adequate psychometric adjustment.

In the present research, we tested the special instrument designed to study the university teacher's explanation behavior, the OPEF. Like the OPTFU, it has showed adequate psychometric adjustment, both in reliability as in homogeneity. Equally, the instrument has been tested by codifying the behavior of one university teacher, and it has showed the possibility of application in a classroom context.

The quality of higher education is a cornerstone in the Bologna process and therefore it is essential to know how the university teachers behave in the instructional stage. The creation of instruments, as we present here, can properly contribute to the assessment of teaching behavior. In addition, given the level of detail with which the university teacher's behavior is studied, there exists the option to analyze and identify the constraints that a specific teacher may have. It is then possible to establish recommendations to improve the quality of teaching and ultimately, the quality of the educational process.

The instrument developed in this research has been tested in order to know its applicability. The results show that teachers make appropriate use of instructional strategies. The most frequently used code is Linear Explanation, which entails exposure of contents, followed in frequency by Explanation with resources and Examples.

Given that the objective is the transmission of content, the teacher uses contrasts stimulus based strategies to a lesser extent, such as use of humor, anecdotes or general interactions. This motivational technique, based on the Gestalt principle figure-background is key to raise the attention of students (Hernández, 1991).

The obtained results in the sequential analysis can discover interesting patterns, which provide much information and contribute to a better understanding of the development of the classes. The university teacher explains the corresponding multimedia content using different materials. The 21st century and the advent of new technologies have introduced new forms of spreading content within the educational context. One of the advantages is the enrichment and enhancement of the attractiveness of the classes.

The linear explanation is also accompanied by other strategies, such as connecting with later contents, allowing teachers to give greater coherence to the process. The use of anecdotes can catch people's attention, and the use of examples and 
definitions allows teachers to get feedback on the degree of understanding of the students.

Another significant pattern that emerges is that the teacher employs the use of examples, connecting them with concrete experiences of the student, which is a useful strategy because it allows the clarification and understanding of the content (Jimenez \& Hernandez-Jorge, 2001). This is followed by the linear explanation of the contents and the use of humor.

It is necessary to register and codify behaviors of other university teachers, and if it is possible, of several universities, to test the utility of the instrument created. Nevertheless, the objective of the present research has been reached, which was the design and purifying of an instrument that studies the university teacher' behavior during their professional performance in the classroom.

\section{References}

Anguera, M. T., \& Hernández-Mendo, A. (2013). La metodología observacional en el ámbito del deporte. E-balonmano.com: Revista de Ciencias del Deporte, 9(3), 135-160.

Anguera, M. T., Blanco, A., \& Losada, J. L. (2001). Diseños observacionales, cuestión clave en el proceso de la metodología observacional. Metodología de las Ciencias del Comportamiento, 3(2), 135-160.

Ausubel, D. P. (1968) Educational Psichology: A congnitive view. New York: Holt.

Bakeman, R., \& Quera, V. (1996). Análisis de la interacción. Análisis Secuencial con SDIS y GSEQ. Madrid: Ra-Ma.

Blanco, A., Sastre, S., \& Escolano, E. (2010). Desarrollo ejecutivo temprano y Teoría de la Generalizabilidad: bebés típicos y prematuros. Psicothema, 22(2), 221-226.

Blanco-Villaseñor, A. (1991). La Teoría de la Generalizabilidad aplicada a diseños observacionales. Revista Mexicana de Análisis de la Conducta, 17(3). 23-63.

Boekaerts, M. (2002). Motivación para aprender. Bruselas: Academia Internacional de Educación

Borges, A., \& Rodríguez-Dorta, M. (2015). Assessment of the Teaching Quality of Teachers of Primary and Special Education. In Roberta V. Nata (Ed.): Progress in Education, 35, 83-104.

Castellano, J., Hernández-Mendo, A., Gómez de Segura, P., Fontetxa, E., \& Bueno, I. (2000). Sistema de codificación y análisis de la calidad del dato en el fútbol de rendimiento. Psicothema, 12(4), 635-641.

Cohen, J. (1960). A coefficient of agreement for nominal scales. Educational and Psychological Measurement, 20, 37-46.

Cronbach, L. J., Gleser, G. C., Nanda, H., \& Rajaratnam, N. (1972). The dependability of behavioral measurements: theory of generalizability for scores and profiles. Nueva York: John Wiley and Sons.

Danielson, C. (2007). Enhancing professional practice: a framework for teaching. Alexandria, VA: Association for Supervision and Curriculum Development.

DePry, R., \& Sugai, G. (2002). The effect of active supervision and Precorrection on Minor Behavioural incidents in a sixth grade general education classroom. Journal of Behavioural Education, 11(4), 255-267.

Díaz, M. C. (2014). Protocolo de Observación de Funciones Docentes en Universidad: Un instrumento para la evaluación de la conducta del profesorado universitario. Tesis Doctoral. Universidad de La Laguna. Soportes Audiovisuales e Informáticos.

Gacía, L. A. (1998) Psicología instruccional e intervención para la mejora cognitiva. Memoria de Cátedra, Universidad de La Laguna.

Galán, A., González-Galán, M. A., \& Rodríguez-Patrón, P. (2014). La evaluación del profesorado universitario en España. Sistema nacional y divergencias territoriales. Revista de Educación, 366, 136-164. http://dx.doi.org/10.4438/1988-592X-RE-2014-366-279

Hernández, P. (1991). Psicología de la Educación: corrientes actuales y teorías aplicadas. Méjico: Trillas.

Hernández, P. (2005). Educación del pensamiento y de las emociones. Tenerife: Tafor/Narcea.

Hernández, P. (2006). Educación del Pensamiento y las Emociones. Tenerife: Tafor/Narcea.

Hernández, P., \& García, L. (1995) Análisis y organización de los contenidos. En P. Hernández (comp) Diseñar y enseñar: Teoría y técnicas de la programación y del proyecto docente. Madrid: Narcea.

Hernández-Jorge, C. (2005). Habilidades de comunicación para profesionales. Tenerife: ARTE Comunicación Visual.

Jiménez, H., \& Hernández-Jorge, C. (2001). ¿Cómo comunicarnos eficazmente en la enseñanza? La comunicabilidad didáctica. En A. Rodríguez (coord.), Psicología de la Instrucción para enseñantes, Las Palmas de Gran Canaria: Instituto Psicosocial Manuel Alemán, 183-197. 
La Paro, K. M., Pianta, R. C., \& Stuhlman, M. (2004). The Classroom Assessment Scoring System: Findings from the Prekindergarten Year. The Elementary School Journal, 104(5), 409-426.

Lane, K., Wehby, J., \& Menzies, H. (2003). Social skills instruction for students at risk for antisocial behaviour. The effects of sall-group instruction. Behavioural Disorders, 28, 229-248.

Martínez, J. F. (2013). Combinación de mediciones de la práctica y el desempeño docente: consideraciones técnicas y conceptuales para la evaluación docente. Pensamiento educativo. Revista de Investigación Educacional Latinoamericana, 50(1), 4-20.

Martínez-Rizo, F. (2012). Procedimientos para el estudio de las prácticas docentes. Revisión de la literatura. Revista Electrónica de Investigación y Evaluación Educativa, 18(1), 1-22. Retrieved in: http://www.uv.es/RELIEVE/v18n1/RELIEVEv18n1_1.htm.

Mateo, J. Y., \& Martínez, F. (2008). La evaluación alternativa de los aprendizajes. Barcelona: Octaedro.

Muñoz de Bustillo, C., \& Rodríguez, A. (2001). ¿Cómo interactuar con los alumnos sin que la clase se nos escape de las manos? Las funciones de relación interpersonal y de regulación del grupo de clase. En A. Rodríguez (coord.), Psicología de la Instrucción para enseñantes, Las Palmas de Gran Canaria: Instituto Psicosocial Manuel Alemán, 229-258.

Ramos, F. J., Hernández-Mendo, A., Pastrana, J. L., \& Blanco, A. (2012). SGAT: Software para la Aplicación de la Teoría de la Generalizabilidad v 1.0. (Proyecto fin de carrera). Ingeniería Técnica en Informática de Gestión de la Escuela Técnica Superior de Ingeniería Informática. Universidad de Málaga.

Rodríguez-Dorta, M., \& Borges, A. (2015). Optimización del tiempo y número de sesiones para la observación de las Funciones Docentes en Educación Primaria y Especial. En A. Borges \& S. Hess (coord.) Libro de Actas del XIII Congreso de Metodología de las Ciencias Sociales y de la Salud, La Laguna: Servicio de Publicaciones de la Universidad de La Laguna, 85-96.

Rodríguez-Dorta, M., Cadenas, M., \& Díaz-Hernández, M. (2011). Estimación del tiempo de registro óptimo para la observación de las funciones docentes del profesor universitario. Revista de Investigación y Divulgación en Psicología y Logopedia, 1(1), 10-15.

Rodríguez-Naveiras, E. Borges, A., \& Cadenas, M. (2013). Creating and purifying an observation instrument using the generalizability theory. Acción Psicológica, 10(2), 73-86. http://dx.doi.org/10.5944/ap.10.2.11825.

Román, M., \& Murillo. J. F. (2013). Evaluación en el campo educativo: del sentido a la práctica (editorial). Revista Iberoamericana de Evaluación Educativa, 6(1), 7-12.

Sarriá, E. (2010). La observación. En S. Fontes, C. García-Gallego, L. Quintanilla, R. Rodríguez, P. Rubio y E. Sarriá Fundamentos de investigación en Psicología , 313- 353.

Schuldheisz, J. M., \& Van der Mars, H. (2001). Active supervision and students' physical activity in middle school physical education. Journal of Teaching in Physical Education, 21, 75-90.

Volpe, R. J., Briesch, A. M., \& Gadow, K. D. (2011). The efficiency of behaviour rating scales to assess inattentive-overactive and oppositional-defiant behaviours: Applying generalizability theory to streamline assessment. Journal of School Psychology, 49, 131-155. http://dx.doi.org/10.1016/j.jsp.2010.09.005

Yule, G. V., \& Kendall, M. G. (1957). An introduction to the theory of statistics. London, England: Griffin.

\section{(cc) $\mathrm{BY}$}

This work is licensed under a Creative Commons Attribution 3.0 License. 